\title{
A Rare Case Report of Calcium Channel Blocker Induced Hypothyroidism
}

\author{
Joshisree K P ${ }^{1}$, Dr Siddarama $\mathbf{R}^{2}$ \\ ${ }^{1}$ Pharm D, Department of Pharmacy Practice, Creative Educational Society's College of Pharmacy, N.H. 4, Chinnatekur, Kurnool, Andhra \\ Pradesh, India 518218 \\ ${ }^{2}$ Assistant Professor, Department of Pharmacy Practice, Creative Educational Society's College of Pharmacy, N.H. 4, Chinnatekur,
} Kurnool, Andhra Pradesh, India 518218

\begin{abstract}
Calcium channel blockers (CCBs) are commonly used drugs for cardiovascular conditions like hypertension, angina and arrhythmias. The effect of this drug on other system was not given importance. Here we reported a case of female patient of 45 years old who was conformed to hypertension and diabetes using tab amlodipine (for hypertension) and oral hypoglycaemic agents (for diabetes) since 1 year. While patient was on therapy hypothyroidism was noticed. De-challenge was done. The relation between suspected drug and Adverse drug reaction(ADR) was established by performing ADR assessment scales like Naranjo's scale and WHO UMC scale shows probable ADR. So, clinical pharmacist plays an important role in monitoring, detecting, and managing the ADR.
\end{abstract}

Keywords: Calcium channel blockers (CCBs), hypothyroidism, amlodipine, adverse drug reaction(ADR).

\section{Introduction}

Hypothyroidism is increasing in its prevalence as time is progressing. It has been attributed to various causes like pollution levels and long term usage of drugs causing chemical injury to thyroid.A large population approximately $20 \%$ in south India are hypertensive who are put on one or the other antihypertensive therapy, with calcium channel blockers being one of the important treatment modality in elderly patients above 55years[1].

Thus the administration of calcium channel blockers(CCBs) may affect these hormones at some levels. Although, it is difficult to delineate the exact mechanism of these drugs, but as the name itself suggests that the CCBs act by blocking the calcium channels thus altering the calcium concentrations inside the cells. They inhibit the entry of calcium through these channels in those tissues in which depolarisation is dependent on calcium rather than on sodium influx; these include vascular smooth muscles, myocardial cells and cells of sino-atrial and atrioventricular nodes. Several reports are available to justify the action of CCBs on hormones. Studies in vivo showed that, $\mathrm{CCB}$ s inhibited the endogenous TRH (thyroid releasing hormones) synthesis with a subsequent decrease in TSH (thyroid stimulating hormones) stored or alternatively it may alter in some way the intracellular stores of calcium which prevented TSH release from the thyrotropin and stimulation of TSH beta gene transcription requires calcium release from inositol triphosphate sensitive stores and calcium ion influx via L type calcium channel [2].

One month oral therapy with calcium channel blockers caused significant $(\mathrm{P}<0.001)$ decrease in serum levels of triiodothyronine and thyroxine and significant increase in serum levels of thyroid stimulation hormones. Most probable mechanism of action was block in the synthesis and/or release of thyroid hormones [3].
Calcium channel blockers, which are prescribed for hypertension, management of Angina include such as verapamil, nifedipine, and amlodipine is known to reduce the secretion of insulin [4].

Incidence: 25,112 people reported to have side effect when taking amlodipine. Among them, 104 people $(0.41 \%)$ have hypothyroidism[5].

Prevalence: Prevalence in urban population is found to be $10.95 \%$. In particular female population being involved is $15.86 \%$ with male population of $5.02 \%$ [1].

\section{Case Report}

A 45 years old female patient admitted in general ward for evaluation and control of blood pressure and blood sugar. After routine examination and investigations, she was diagnosed to have hypertension with blood pressure 140/100; she was prescribed with amlodipine 5mg. After 6 months she was diagnosed to have diabetes type 2 with fasting blood sugar (FBS) $147 \mathrm{mg} / \mathrm{dl}$ and post prandial blood sugar $160 \mathrm{mg} / \mathrm{dl}$, she was prescribed with oral hypoglycaemic agents. Patient was asymptomatic for 1 year. She was investigated further and her thyroid profile was evaluated and it was markedly pointing towards hypothyroid with TSH $3.5 \mu \mathrm{U} / \mathrm{ml}$, T4 $6 \mu \mathrm{g} / \mathrm{dl}$, and T3 70ng/dl; she was prescribed with tab thyroxine $75 \mathrm{mcg}$. Expecting tab amlodipine cause hypothyroidism, antihypertensive treatment was changed to tab Telmisartanhydrochlorothiazide was prescribed. She was on regular check-ups and her diabetic profile and blood pressure looked normal. 


\section{International Journal of Science and Research (IJSR) \\ ISSN (Online): 2319-7064}

Index Copernicus Value (2016): 79.57 | Impact Factor (2015): 6.391
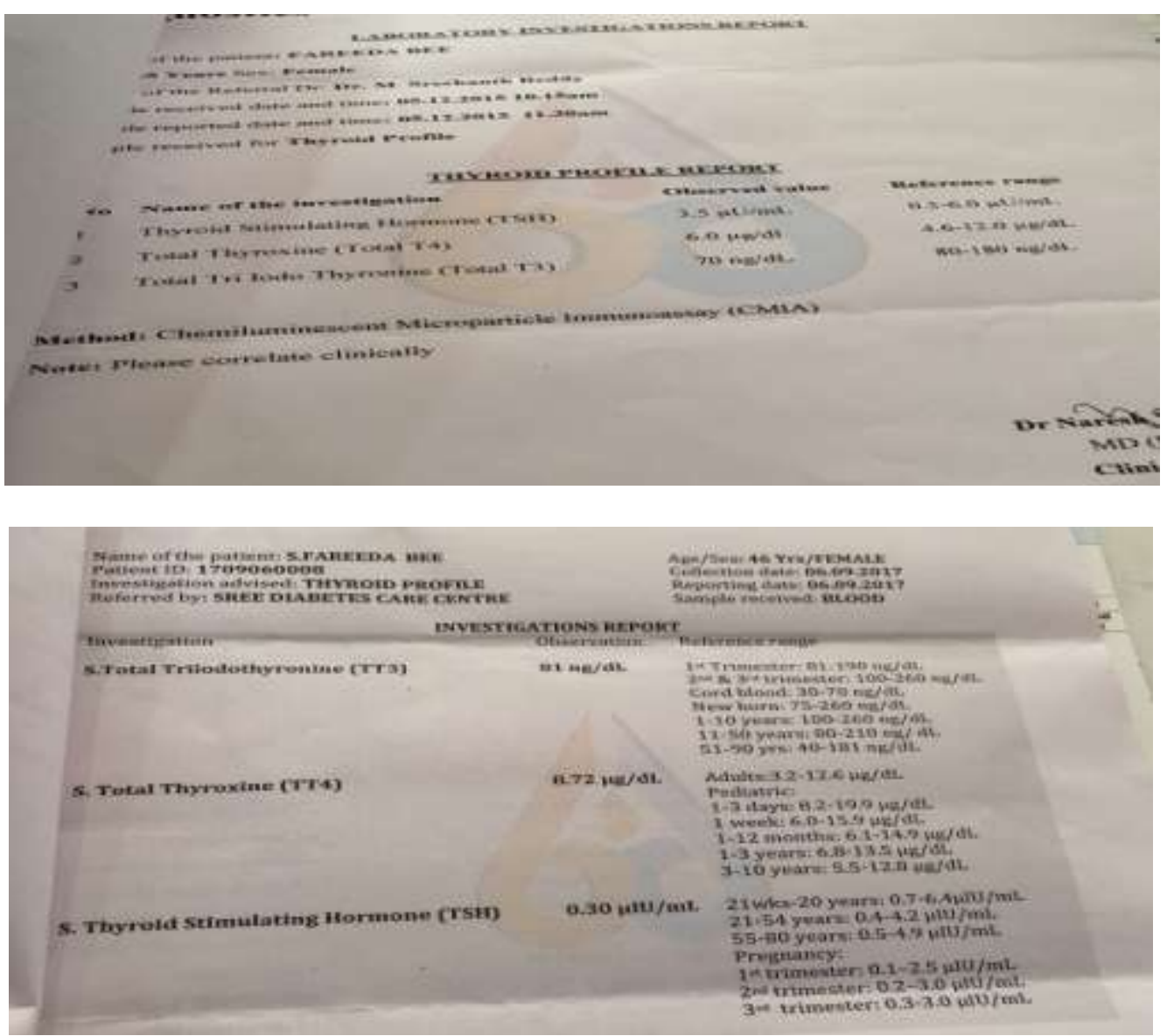

After 2 years, she was evaluated again. Her blood pressure, blood sugar levels and thyroid profile test were normal and she was tapered the dose i.e tab thyroxine $25 \mathrm{mcg}$.

Based on subjective and objective evidence patient was experienced amlodipine induced hypothyroidism. Clinical evaluation was done and patient was treated symptomatically with Glimepiride+ Metformin (for diabetes mellitus),Telma-H( for hypertension), tab levothyroxine $25 \mathrm{mcg}$ (for hypothyroidism) and tab Polybion (for vitamin supplements).

\section{ADR analysis}

\section{Causality assessment}

After collecting past and present history of patient, ADR analysis was done using Naranjo's scale and WHO UMC scale were shown in table 1 and most suspected drug to produce hypothyroidism due to CCBs. Here we also performed severity; predictability and preventability scale of suspected drug were shown in table 2.

\section{Re-challenge: Was not done}

De-challenge: After complete evaluation of the re-challenge the suspected drug i.e amlodipine were stopped administrating.

Table 1: Causality assessment of ADR:

\begin{tabular}{|c|c|c|c|c|}
\hline SNO & Suspected drug & Suspected ADR & $\begin{array}{c}\text { Naranjo's } \\
\text { scale }\end{array}$ & $\begin{array}{c}\text { WHO } \\
\text { UMC }\end{array}$ \\
\hline 1 & Amlodipine & hypothyroidism & $\begin{array}{c}\text { Probable } \\
\text { ADR(6) }\end{array}$ & $\begin{array}{c}\text { Probable } \\
\text { ADR }\end{array}$ \\
\hline
\end{tabular}

Table 2: severity, predictability and preventability of ADR:

\begin{tabular}{|c|c|c|c|c|}
\hline ADR & Drug & Severity & predictability & preventability \\
\hline $\begin{array}{c}\text { Amlodipine } \\
\text { induced } \\
\text { hypothyroidism }\end{array}$ & amlodipine & $\begin{array}{c}\text { Severity } \\
\text { level 3 } 3\end{array}$ & predictability & preventability \\
\hline
\end{tabular}

\section{Discussion}

Hypothyroidism is a major disorder worldwide causing morbidity. Cause of hypothyroidism is mainly considered to be iodine deficiency, autoimmune diseases and post thyroidectomy, drug induced, familial and idiopathic. Amlodipine being a calcium channel blocker can cause hypothyroidism by blocking L-type Ca $2+$ channels, which in turn cause decreased secretion as well as efflux of thyroid hormone [1].

CCRs are used widely in day-to-day practice and there are some scattered evidences that these agents might be affecting endocrinal physiology. Several CCBs are known to affect serum levels of tri-iodothyronine, thyroxine and thyroid stimulating hormone. Some studies showed low serum levels of tri-iodothyronine and thyroxine in some patients receiving CCBs namely- Verapamil, Nifedipine and Diltiazem. Our study also suggests that amlodipine may decrease the serum levels of T3, T4 and increase in TSH levels [2].

The main clinical use of CCBs is in the management of various cardiovascular diseases. On the basis of the observations of the present study, it is clear that on long term calcium channel blocker therapy the functioning of

Volume 6 Issue 12, December 2017 


\section{International Journal of Science and Research (IJSR) \\ ISSN (Online): 2319-7064}

Index Copernicus Value (2016): 79.57 | Impact Factor (2015): 6.391

endocrine system is disrupted. Following could be the possible mechanism for these changes:

- Due to interference with the synthesis and release of hormone

- Due to alteration in the regulatory process of these hormones

Some recent studies showed that, they are 9 common drugs that every diabetic should avoid mixing with their medicines. They are:

1) Beta blockers

2) Minoxidil

3) Thiazide diuretics

4) Calcium channel blockers

5) Oral contraceptives

6) Corticosteroids

7) Niacin

8) Dyphenylhydantoin

9) Thyroid hormones

For most of these, the side effects will be to cause blood glucose to rise. As I point out elsewhere, people with diabetes should plan to check their blood glucose for at least 3 days any doctor changes any of your medications. That advice applies to these 9 medications, and to any other new drug whether prescription or over-the-counter [4].

\section{Conclusion}

Daily use of calcium channel blockers(CCBs) amlodipine may cause hypothyroidism in some patients. Patient should be educated regarding such rare associations and encourage them for frequent check-ups should be done every month and report any symptoms like weight gain, lethargy and hair loss. Clinical pharmacist should play a major role in detecting, monitoring and managing the ADRs. This study proposes the importance of blood thyroid levels follow up in long term CCBs therapy and precautions should be taken and proper monitoring of blood thyroid levels for patients who receive long term CCBs therapy.

\section{Authors Contribution}

K.P.Joshisree: followed the case, took the detailed history of study and wrote the case study

R.Siddarama: helped in structuring the paper.

\section{References}

[1] Pruthvi Desireddy1, Praveena Gungam2 , Souris Kondaveti3, Swathi 4, A rare case report of calcium chaneels blockers induced subclinical hypothyroidism, journal of evidence based medicine and health care, 2015,2(18), p: 2795-2800

[2] Rimple J.Kaur1, Bharati Mehta2, Sneha R, Ambwani3, AnushaGehlot, Effect of calcium channel blockers on the serum levels of thyroid hormone, international journal of basic and clinical pharmacology, 2013, 2(4),p:476-477

[3] Mittal SR1, Mathur AK, Prasad N, Effect of calcium channel blockers on serum levels of thyroid hormones, Int J cardiol, 1993, 38(2), p:131-132
[4] Bill Quick, M.D, Nine drugs, Diabetes, https://www.healthcentral.com/article/nine-drugs [Last accessed on 21 Aug 2009]

[5] Amlodipine besylate and hypothyroidism-from FDA reports, http://www.ehealthme.com/ds/amlodipinebesylate/hypothyroidism/ [Last accessed on 21 Sep 2017]

Volume 6 Issue 12, December 2017 